\title{
Antibacterial Activity and Chemical Composition of Crude Extract and Oil of Zygophyllum (Fagonia) luntii (Baker) 1894 (Family Zygophyllaceae)
}

Riaz Shah ${ }^{1 *}$, Suad J.A. Alabri ${ }^{2}$, Ameera S.M Ashehi ${ }^{2}$, Nasser S.S. Asiyabi ${ }^{2}$, Wafa K.A. AlMamari ${ }^{2}$, Jamal N. AlSabahi ${ }^{3}$ Huda Al-Ruqaishi ${ }^{3}$

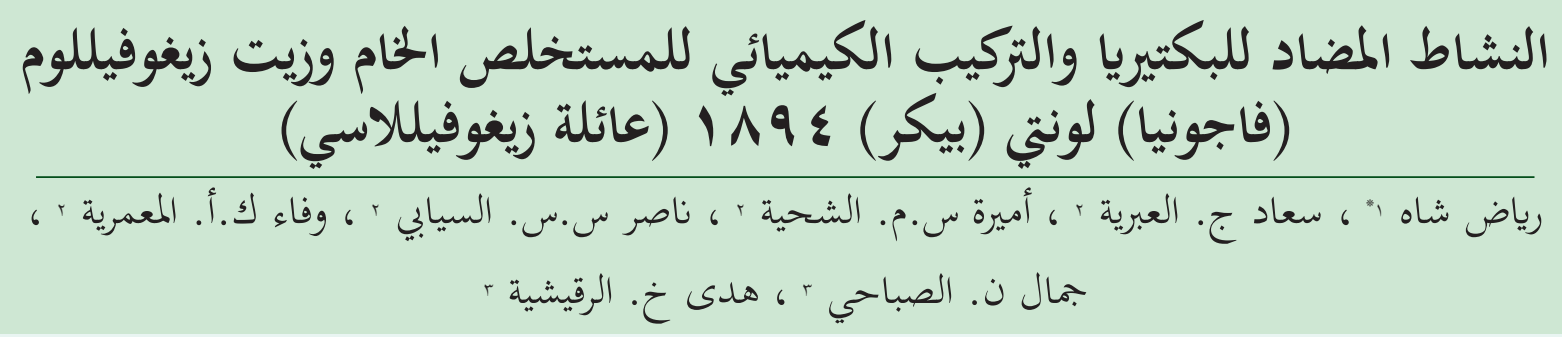

ABstraCT. Wild plants such as Zygophyllum luntii, from the Zygophyllaceae family, have traditionally been used for medicinal purposes in Oman. The present study investigated (i) the antibacterial activity of the crude extracts (leaves, stem and roots) and the oil (leaves); and (ii) the hydrocarbon contents and fatty acid methyl ester (FAME) components from Z. luntii. These extracts were tested against Escherichia coli, Staphylococcus aureus, and Pseudomonas aeruginosa using well diffusion assays utilizing Muller Hinton Agar (MHA). Antibacterial activity was observed with the Z. luntii leaf extract and significant differences $(\mathrm{F}=14.06, \mathrm{df}=2, \mathrm{P}=0.002)$ were found among $E$. coli, $P$. aeruginosa and $S$. aureus. The highest inhibition was observed against $P$. aeruginosa, with an inhibition zone of $15.5 \pm 2.6 \mathrm{~mm}$, followed by $E$. coli and $S$. aureus with inhibition zones of $11.3 \pm 1.5 \mathrm{~mm}$ and $3.5 \pm 4.7 \mathrm{~mm}$, respectively. The $Z$. luntii extracts showed effectiveness within 50-60\% against E. coli and P. aeruginosa as compared to Ciprofloxacin. The hydrocarbon contents and the FAME components of the extracts were determined with Gas Chromatography-Mass Spectrometry (GC-MS). A total of 20,19, and 8 compounds were detected from leaf, stem, and root extracts, respectively. Heneicosane, docosane, and tricosane were found in the highest concentration in the leaves, HOP-22(29)-EN-3.BETA.-OL and $\beta$-sitosterol were found in the stems, and docosane and tricosane were found in the roots of $Z$. luntii. Nine types of fatty acids methyl esters were detected in the oil extracted from leaves with methyl esters of palmitic acid, linolenic acid, and oleic acid constituting $90 \%$ of the oil. This is the first report on antibacterial activity and chemical composition of $Z$. luntii.

KeYwords: Zygophyllum luntii, Antibacterial activity, Gas Chromatography- Mass Spectrometry (GC-MS), Fatty Acid Methyl Ester (FAME)

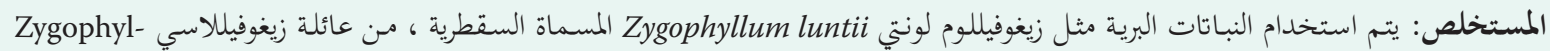

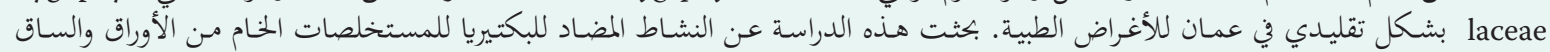

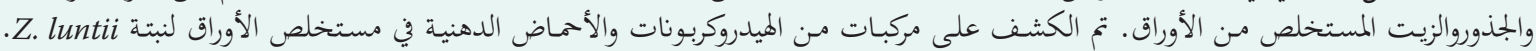

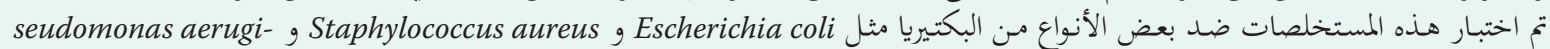

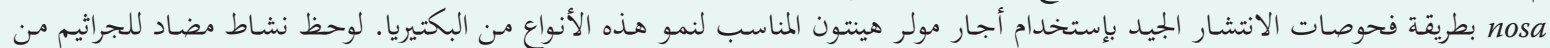

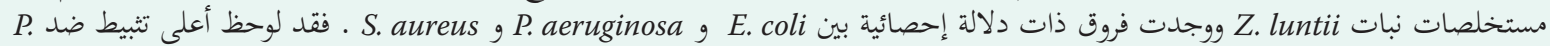

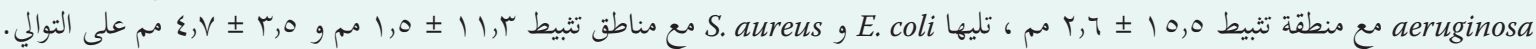

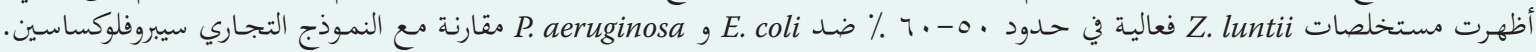

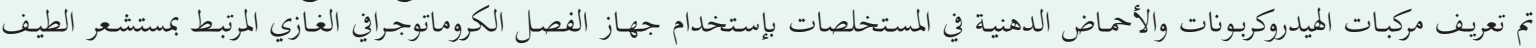

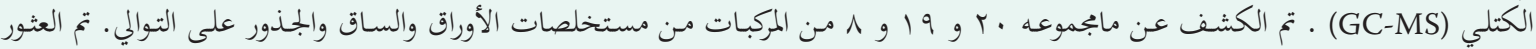

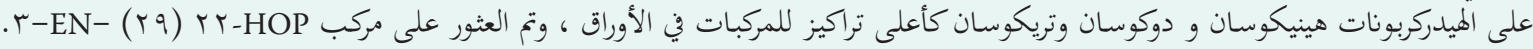

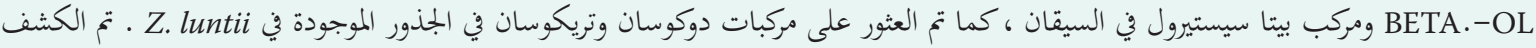

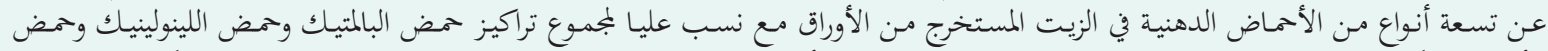

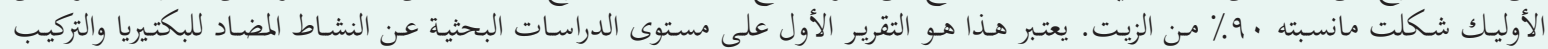

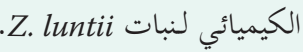

لكلمات المفتاحية: زيغوفيللوم لونتي ، النشاط المضاد للبكتيريا ، جهاز الفصل الكروماتوجرافي الغازي المرتبط بالطيف الكتلي (GC-MS) ، الأماض الدهنية الميثيل إستر (FAME)

Riaz Shah ${ }^{1 *}(\square)$ riazshah@squ.edu.om, ${ }^{1}$ Department of Plant Sciences, College of Agricultural and Marine Sciences, Sultan Qaboos University, Al-Khoud-123, Muscat, Sultanate of Oman. ${ }^{2}$ College of Science, Sultan Qaboos University, Al-Khoud-123, Muscat, Sultanate of Oman. ${ }^{3}$ Central analytical laboratory, College of Agricultural and Marine Sciences, Sultan Qaboos University, Al-Khoud-123, Muscat, Sultanate of Oman.

\section{Introduction}

A round $80 \%$ of the world population use traditional medicine which is often based on medicinal plants (Martins, 2013; Oyebode et al., 2016). Around $75 \%$ of commercial drugs launched in the world 
global market yearly are extracted or isolated from natural resources and about $25 \%$ of the prescribed pharmaceutical drugs are based on plant chemicals (Orhan, 2012). Plants are the major source of secondary metabolites, which are used to treat various diseases (Hossain et al., 2013; Akhtar et al., 2017; Raqiya and Hossain, 2017; Asma et al., 2017; Hossain, 2018; Said et al., 2018). Medicinal plants are found in many places in the world; however, they are found more in tropical regions (AlSalt, 2012).

Family Zygophyllaceae includes many medicinally important plants spices including several species of Zygophyllum. Zygophyllum have antitumor, antioxidant and analgesic properties, and have been used for the treatments of cancer, fever, asthma, urinary discharges, toothache, stomach problems and kidney diseases (Ahsan et al., 2007; Satpute et al., 2009). Zygophyllum species were found to be potent antifungal and antibacterial agents (Zhang et al., 2008; Gupta et al., 2009) and contained many biologically active chemical constituents, such as alkaloids, saponins, terpenoids, sterols, flavonoids, coumarins and trace elements (Beier, 2005).

Zygophyllum luntii distribution is restricted to the Horn of Africa region, including Djibouti, Oman, Somalia and Yemen (Beier, 2005). It grows on sand as well as gravel, from sea level up to $1950 \mathrm{~m}$ altitude. In Oman, $Z$. luntii is found in the foot of Dhofar mountains along with several other species of Zygophyllum (Z. bruguieri, schweinfurtii, indica, mahrana and ovalifolia) (Mosti, et al., 2012).

The current study explored two objectives. Firstly, antibacterial activity of the $Z$. luntii extract (leaves, stems and roots) and leaf oil against Escherichia coli, Staphylococcus aureus and Pseudomonas aeruginosa were investigated. Secondly, hydrocarbon contents of the plant extracts and lipids fatty acid methyl ester were determined (FAME) components of the oil extracted from leaves by gas chromatography- mass spectrometer (GC-MS).

\section{Materials and Methods}

\section{Collection and Preparation of Plant Materials}

Roots, leaves, and stems of $Z$. luntii were gathered from the Botanical Garden at Sultan Qaboos University, Oman. These parts were cleaned with tap water followed by distilled water to remove any dust and soil. The plant parts were then further divided into two portions; one was dried in the oven at $70^{\circ} \mathrm{C}$ for $8 \mathrm{~h}$ and then ground into a fine powder and other portion was kept fresh in a refrigerator at $4^{\circ} \mathrm{C}$.

\section{Plant Extracts Preparation for Anti-bacterial Test}

The dried powder of the leaves, stem and roots was dissolved in $70 \%$ methanol $(1: 3, \mathrm{w} / \mathrm{v})$ and then kept in a shaker for extraction at room temperature for $24 \mathrm{~h}$.
Then, methanol was dissipated from the sample using oven to get the crude extract which was re-suspended in dimethylsulfoxide (DMSO) for application in the antibacterial test.

\section{Lipid Extraction from Leaves}

Around $470 \mathrm{~g}$ of the fresh leaves with $1 \mathrm{~L}$ of distilled water were grinded by a blender. The solution was mixed with the solvent (chloroform: methanol in 2:1 ratio) to separate the lipids and then evaporated in a rotary evaporator. The extract was filtered through charcoal. The obtained oil ( $1 \mathrm{~g})$ was kept in storage at $4^{\circ} \mathrm{C}$ until utilization for further tests.

\section{Anti-bacterial Assay}

Muller Hinton Agar CM0337 from Oxiod (Part of Thermo Fisher Scientific) was used in well diffusion assay. MHA contains beef dehydrated infusion $300.0 \mathrm{~g} / \mathrm{L}$, casein hydrolysate $17.5 \mathrm{~g} / \mathrm{L}$, starch $1.5 \mathrm{~g} / \mathrm{L}$ and agar 17.0 $\mathrm{g} / \mathrm{L}$. Amount of $38 \mathrm{~g}$ of MHA was suspended in $1 \mathrm{~L}$ of distilled water, boiled and sterilized by autoclaving at $121^{\circ} \mathrm{C}$ for $15 \mathrm{~min}$.

Three strains of pathogenic bacteria E. coli ATCC 25922, P. aeruginosa ATCC 27853, and S. aureus ATCC 25923 were utilized as test microorganisms. These clinical isolates were obtained from Microbiology Laboratory at Sultan Qaboos University Hospital. These strains are for antibiotic testing and fall under the American type collection culture (ATCC). Furthermore, these strains were sub cultured in liquid broth for a period of 6 to 8 hours. The well diffusion assay was conducted utilizing Muller Hinton Agar (MHA). The assay of leaves, stem and roots extract activity was carried out in nine MHAs plates which were replicated three times. For every plate, four discs were used one each for leaves, stem, roots and an antibiotic standard (Ciprofloxacin) as positive control. Discs of 6 - $8 \mathrm{~mm}$ diameter were removed from agar with a sterile glass pasture pipette and filled with $30 \mu \mathrm{l}$ of the sample extract or standard. At the same time, three MHAs plates were used for oil using a similar procedure where three discs were used for every plate; two discs for oil and one disc for antibiotic standard. Zone inhibition was investigated after incubating agar plates at $37^{\circ} \mathrm{C}$.

\section{Sample Preparation and Extraction for GC-MS Analysis}

Fresh leaf, stem and root samples were weighed and grinded using a mechanical grinder. Then, $50 \mathrm{~mL}$ of $70 \%$ methanol was added to each grinded sample and placed in an ultrasonic water bath working at $50-60 \mathrm{kHz}$ with power of $350 \mathrm{~W}$ for $30 \mathrm{~min}$ at room temperature. By using a rotary vacuum evaporator, the methanol was evaporated and the extracts were concentrated. The crude extracts were dissolved in hexane, filtered by microfiltration $(0.45 \mu \mathrm{l}$ syringe $)$ and injected to GC-MS. 

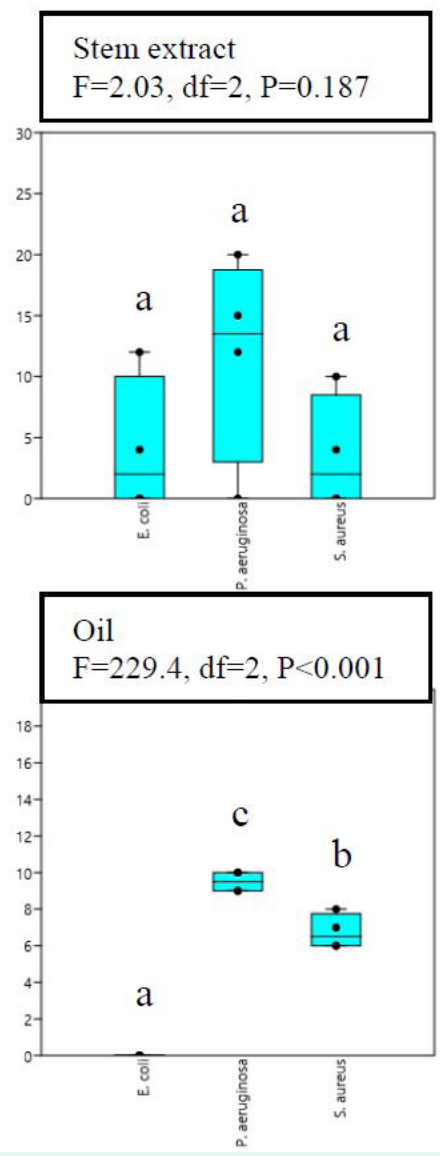
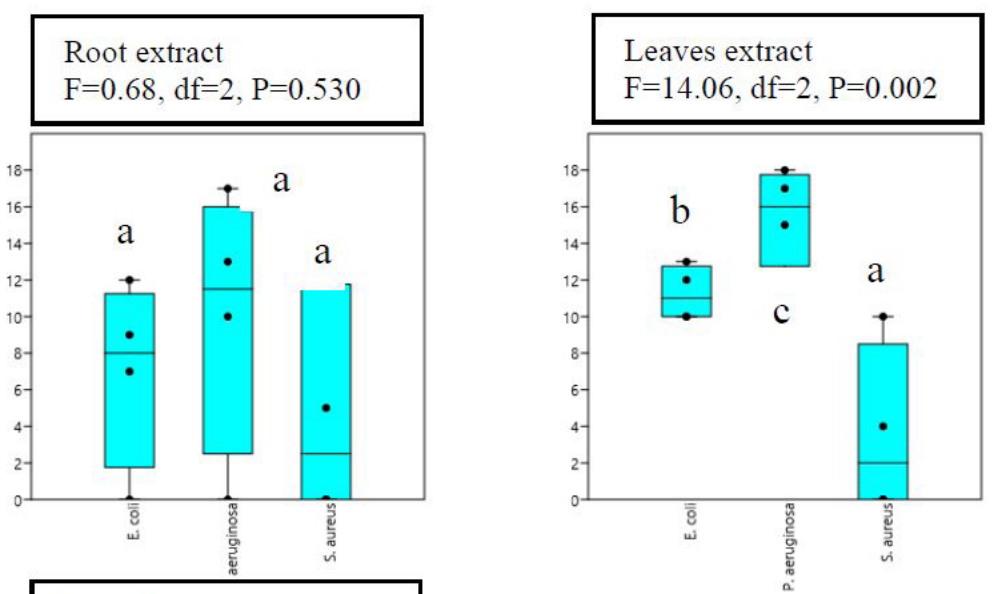

Ciprofloxacin

$\mathrm{F}=73.3, \mathrm{df}=2, \mathrm{P}<0.001$

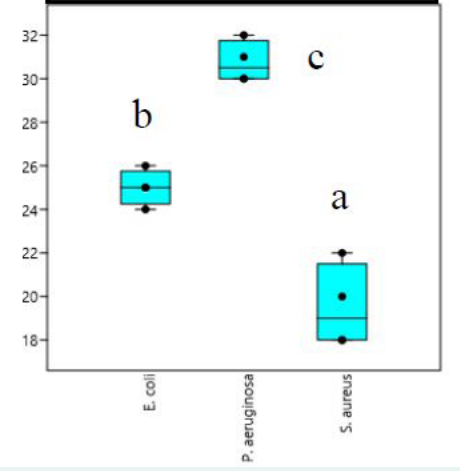

Figure 1. Comparison of anti-bacterial activity (inhibition zone in $\mathrm{mm}$ ) among Escherichia coli ATCC 25922, Staphylococcus aureus ATCC 25923 and Pseudomonas aeruginosa ATCC 27853 in well diffusion assays exposed to Zygophyllum luntii extracts and Ciprofloxacin. Bars designated by the same letters are not statistically significant at $\alpha_{0.05}$

Gas Chromatography-Mass Spectrometry (GC/ MS) Analysis

GC-MS conditions for samples extracted from leaves, stem and roots: GC-MS analysis was performed on a
Perkin Elmer Clarus 600 GC System, fitted with a Rtx5MS capillary column $(30 \mathrm{~m} \times 0.25 \mathrm{~mm}$ i.d. $\times 0.25 \mu \mathrm{m}$ film thickness; maximum temperature, $350^{\circ} \mathrm{C}$ ), coupled to a Perkin Elmer Clarus 600C MS. Ultra-high puri-
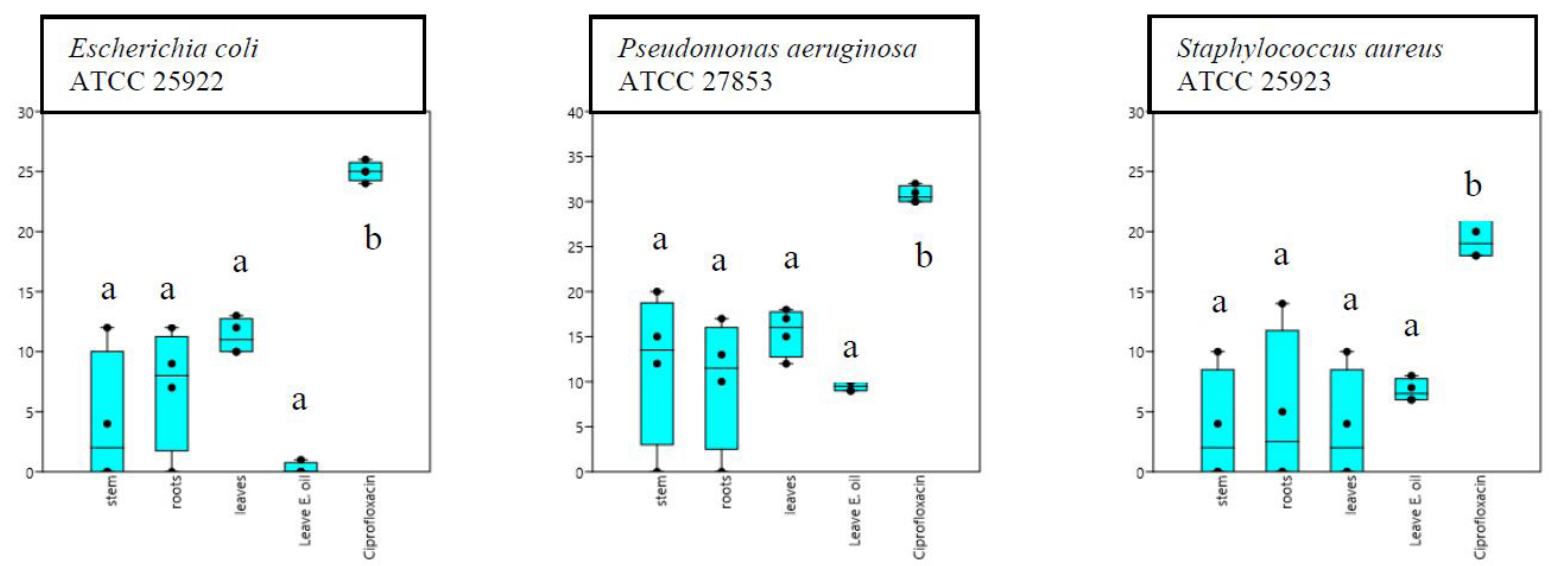

Figure 2. Comparison of anti-bacterial activity (inhibition zone in $\mathrm{mm}$ ) of the Zygophyllum luntii extracts and Ciprofloxacin against Escherichia coli ATCC 25922, Pseudomonas aeruginosa ATCC 27853 and Staphylococcus aureus ATCC 25923 well diffusion assays. Bars designated by the same letters are not statistically significant at $\alpha_{0.05}$ 
Table 1. Compounds identified in the leaf, stem and root extracts of Zygophyllum luntii by GC-MS

\begin{tabular}{|c|c|c|}
\hline Name of compound & $\begin{array}{c}\text { Retention } \\
\text { Time } \\
\text { (min) }\end{array}$ & Percent (\%) \\
\hline \multicolumn{3}{|c|}{ Leaves } \\
\hline Pentadecane & 13.64 & 0.33 \\
\hline Tetradecane, 2,6,10-trimethyl- & 16.43 & 0.68 \\
\hline Oxalic acid, allyl octyl ester & 16.81 & 0.32 \\
\hline Unidentified & 17.02 & 0.61 \\
\hline Octadecane & 17.79 & 0.34 \\
\hline Nonadecane & 18.73 & 0.90 \\
\hline Eicosane & 19.02 & 5.84 \\
\hline Heneicosane & 21.57 & 12.30 \\
\hline Docosane & 22.60 & 12.72 \\
\hline Tricosane & 23.26 & 12.93 \\
\hline Tetracosane & 24.24 & 9.94 \\
\hline Pentacosane & 25.36 & 10.42 \\
\hline Hexacosane & 26.21 & 7.63 \\
\hline Heptacosane & 27.13 & 5.84 \\
\hline Octacosane & 27.87 & 5.82 \\
\hline Nonacosane & 28.70 & 5.03 \\
\hline Triacontane & 29.62 & 4.10 \\
\hline Hentriacontane & 30.71 & 1.84 \\
\hline Dotriacontane & 31.99 & 2.42 \\
\hline Tetratriacontane & 36.24 & 0.13 \\
\hline \multicolumn{3}{|c|}{ Stem } \\
\hline Hexadecanal & 18.33 & 2.60 \\
\hline Phytol & 21.50 & 5.22 \\
\hline Unidentified & 22.22 & 2.70 \\
\hline Unidentified & 23.20 & 0.38 \\
\hline Unidentified & 24.20 & 0.27 \\
\hline Unidentified & 25.18 & 0.47 \\
\hline Heptacosane & 26.90 & 0.35 \\
\hline Octacosane & 27.80 & 0.22 \\
\hline Supraene & 28.14 & 0.95 \\
\hline Unidentified & 28.60 & 0.46 \\
\hline Triacontane & 29.50 & 0.29 \\
\hline Hentriacontane & 30.64 & 0.38 \\
\hline Vitamin E acetate & 31.40 & 1.24 \\
\hline Dotriacontane & 31.93 & 0.64 \\
\hline
\end{tabular}

\begin{tabular}{lcc|}
\hline \multicolumn{1}{|c}{ Name of compound } & $\begin{array}{c}\text { Retention } \\
\text { Time } \\
(\mathbf{m i n})\end{array}$ & Percent (\%) \\
\hline Tritriacontane & 33.40 & 1.23 \\
$\beta$-Sitosterol & 34.36 & 11.02 \\
Heptatriacontane & 35.40 & 0.80 \\
Hop-22(29)-En-3.Beta.-Ol & 35.90 & 69.95 \\
Octatriacontane & 37.70 & 0.84 \\
\hline Docosane & 22.60 & 14.04 \\
\hline Tricosane & 23.49 & 14.36 \\
Tetracosane & 24.43 & 12.54 \\
Pentacosane & 25.36 & 4.02 \\
Pentacosane & 25.54 & 5.33 \\
Hexacosane & 26.24 & 6.67 \\
Octacosane & 27.13 & 43.05 \\
Tetratriacontane & 36.24 & 1.15 \\
\hline
\end{tabular}

ty helium (99.9999\%) was used as carrier gas at a constant flow of $1.0 \mathrm{~mL} / \mathrm{min}$. The injector, transfer line and ion source temperatures were $280^{\circ} \mathrm{C}, 270^{\circ} \mathrm{C}$ and $270^{\circ} \mathrm{C}$, respectively. The ionizing energy was $70 \mathrm{eV}$. Electron multiplier (EM) voltage was obtained from auto tune. All data were obtained by collecting the full-scan mass spectra within the scan range 40-550 amu. The injected sample volume was $1 \mu \mathrm{l}$ with a split ratio of $10: 1$. The oven temperature program was $60^{\circ} \mathrm{C}$ at a rate of $80^{\circ} \mathrm{C}$ per minute to $280^{\circ} \mathrm{C}$ hold for 25 minutes. The total run time was 53.5 minutes.

GC/MS conditions for the oil extracted from leaves: Fatty Acid Methyl Ester (FAME) compounds were detected by the GC-MS equipment as mentioned above. The helium gas flow rate was $0.7 \mathrm{~mL} / \mathrm{min}$. The injector, transfer line and ion source temperatures were $250^{\circ} \mathrm{C}$, $250^{\circ} \mathrm{C}$ and $220^{\circ} \mathrm{C}$, respectively. The initial oven temperature was set at $50^{\circ} \mathrm{C}$ (holds for 8 minutes) and increased to $250^{\circ} \mathrm{C}$ in a rate of $40^{\circ} \mathrm{C}$ per minute. All data were obtained by collecting the full-scan mass spectra within the scan range 35-500 amu. The unknown compounds were identified by comparing the spectra obtained with mass spectrum libraries (NIST 2011 v.2.3 and Wiley, 9th edition).

\section{Statistical Analysis}

Data on antibacterial assays from leaves, stems and roots, and the three bacterial strains were analysed separately using one-way analysis of variance (ANOVA) in Past (https://past.en.lo4d.com/windows). Means were separated by Dunn's Multiple Comparison Test and differences were considered significant at $\mathrm{p}<0.05$. 
Table 2. Compounds detected in the oil extracted from Zygophyllum luntii leaves by GC-MS

\begin{tabular}{|lll|}
\hline \multicolumn{1}{|c}{ Name of compound } & $\begin{array}{c}\text { Retention } \\
\text { Time } \\
\text { (min) }\end{array}$ & Percent (\%) \\
\hline Caprylic acid methyl ester & 11.58 & 0.12 \\
\hline Capric acid methyl ester & 18.27 & 0.19 \\
\hline Lauric acid, methyl ester & 24.29 & 0.74 \\
\hline Myristic acid, methyl ester & 29.83 & 0.81 \\
\hline Palmitic acid, methyl ester & 34.93 & 34.55 \\
\hline Palmitoleic acid, methyl ester & 35.90 & 1.70 \\
\hline Oleic acid, methyl ester & 39.78 & 23.99 \\
\hline Linoleic acid, methyl ester & 40.57 & 5.81 \\
\hline Linolenic acid, methyl ester & 41.73 & 32.09
\end{tabular}

\section{Result and Discussion}

\section{Antibacterial Assays}

Significant antibacterial activity was observed in the $Z$. luntii leaves extract and significant differences $(\mathrm{F}=14.06$, $\mathrm{df}=2, \mathrm{P}=0.002$ ) were found among E. coli, $P$. aerugino$s a$ and $S$. aureus (Figure 1). The highest inhibition was observed against $P$. aeruginosa $(15.5 \pm 2.64 \mathrm{~mm})$ then E. coli $(11.25 \pm 1.50 \mathrm{~mm})$ and $S$. aureus $(3.50 \pm 4.72 \mathrm{~mm})$. The inhibition zones of the stem $(\mathrm{F}=2.03, \mathrm{df}=2, \mathrm{P}=0.187)$ and $\operatorname{root}(\mathrm{F}=0.68, \mathrm{df}=2, \mathrm{P}=0.530)$ extracts did not differ significantly among the three bacterial strains. Oil from leaves did not produce any inhibition in $E$. coli but had significantly higher inhibition $(\mathrm{F}=229.4, \mathrm{df}=2$, $\mathrm{P}<0.001)$ in $P$. aeruginosa $(9.5 \pm 0.58 \mathrm{~mm})$ and $S$. aureus $(6.75 \pm 0.96 \mathrm{~mm})$. Ciprofloxacin had significantly different inhibition zones $(\mathrm{F}=73.3, \mathrm{df}=2, \mathrm{P}<0.001)$ among the three bacterial strains. The highest inhibition zone by the commercial antibiotic was against $P$. aeruginosa $(30.75 \pm 0.96 \mathrm{~mm})$ then $E$. coli of $(25.0 \pm 0.82 \mathrm{~mm})$ and lowest against $S$. aureus $(19.50 \pm 1.91 \mathrm{~mm})$.

The inhibition in the stem, root and leaves extracts, and oil from leave was significantly lower than Ciprofloxacin against $E$. coli $(\mathrm{F}=29.8, \mathrm{df}=4, \mathrm{P}<0.001)$, . aeruginosa $(\mathrm{F}=11.7, \mathrm{df}=4, \mathrm{P}<0.001)$ and $S$. aureus $(\mathrm{F}=9.9, \mathrm{df}=4$, $\mathrm{P}<0.001$ ) (Figure 2). The stem extract was more active against $P$. aeruginosa while root extract was more active against $S$. aureus. Leaves extract showed more activity against $E$. coli. The oil showed some antibacterial activity against $P$. aeruginosa and $S$. aureus but not $E$. coli. Overall, the $Z$. luntii extracts were active against both Gram-positive ( $S$. aureus) and Gram-negative bacteria (E. coli and $P$. aeruginosa), though they were more active against the latter. The ethanol extracts of intact leaf of $Z$. arabica showed an inhibition zone of only $6.08 \mathrm{~mm}$

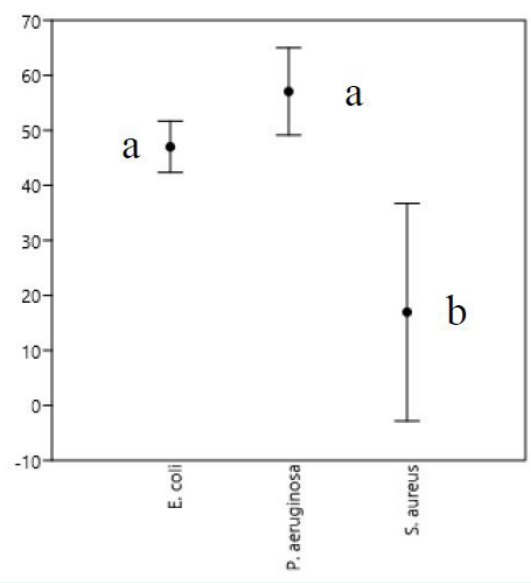

Figure 3. Percent effectiveness of the Zygophyllum luntii extracts compared to Ciprofloxacin against Escherichia coli ATCC 25922, Staphylococcus aureus ATCC 25923 and Pseudomonas aeruginosa ATCC 27853, and S. aureus well diffusion assays. Bars designated by the same letters are not statistically significant at $\alpha_{0.05}$

against $E$. coli and did not inhibit the growth of $S$. aureus (Alam et al., 2010). The ethanol whole plant extract of $F$. cretica produced inhibition zones of $15 \mathrm{~mm}, 15 \mathrm{~mm}$ and $14 \mathrm{~mm}$ against $E$. coli, $P$. aeruginosa and $S$. aureus, respectively (Sajid et al., 2011) which are similar to our results. The crude extract of $Z$. arabica from Sinai showed broad antimicrobial spectrum against Gram-positive, Gram-negative, spore-forming and acid-fast bacteria (El-Hefnawi, 1999). It is obvious that leaves extracts from Zygophyllum spp including Z. luntii have antibacterial properties.

The percent effectiveness of the $Z$. luntii extracts were compared to Ciprofloxacin against E. coli, P. aeruginosa and $S$. aureus by subtracting the extract inhibition zone sizes from the Ciprofloxacin (Figure 3). The calculated percent effectiveness against $E$. coli was 47.0 $\pm 4.8 \%$; against P. aeruginosa was $57.1 \pm 8.1 \%$; and against $S$. aureus was $19.4 \pm 24.2 \%$. The percent effectiveness against $E$. coli and $P$. aeruginosa was significantly higher compared to $S$. aureus $(\mathrm{F}=10.54, \mathrm{df}=2, \mathrm{P}=0.005)$. Alam et al. (2010) produced callus of $Z$. arabica by tissue culture and found that the callus extract was more effective against Serratia marcescens, E. coli and Acetobacter aceti subsp. liquefaciens (inhibition zones $=32.67,33.92$ and $34.83 \mathrm{~mm}$ respectively) than the crude extract of the intact leaf $(I Z=6.08 \mathrm{~mm})$ suggesting higher antibacterial effects of callus extract against Gram - ve bacteria.

Several pathogens are increasingly developing resistance, particularly to broad-spectrum antibiotics (Kunin, 1993). Resistant E. coli isolates have been reported from humans using disk diffusion method against ciprofloxacin (22\% with the highest of $52 \%$ reported from Iran), cefotaxime $(31.2 \%-58 \%)$ and ceftazidime $(10 \%-57.4 \%)$ (Pormohammad et al., 2019). Some of the gram-positive drug resistant bacteria include S. aureus, Streptococcus 

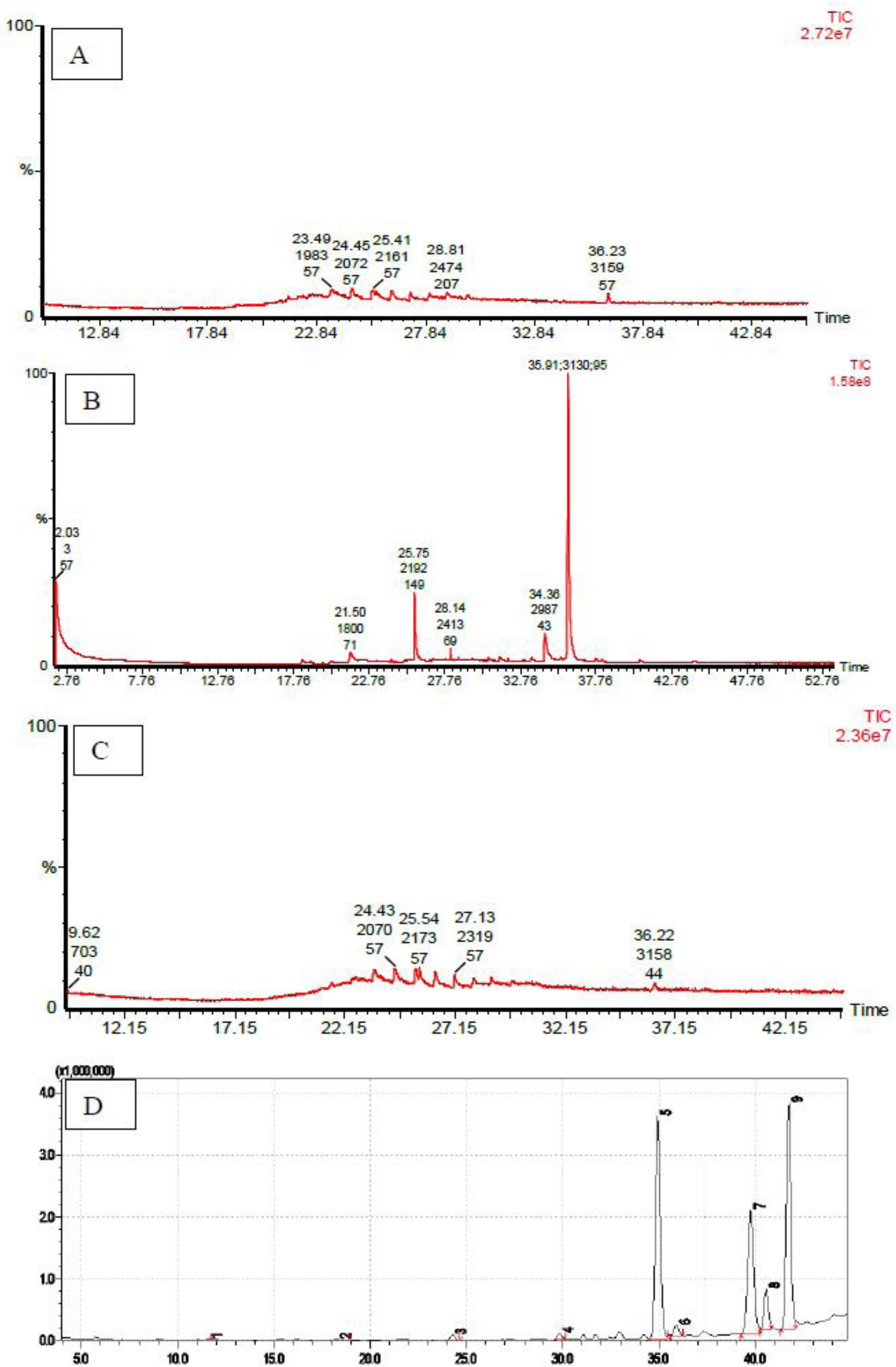

Figure 4. Chromatogram of compounds in leaves (A), stem (B) and roots (C), and fatty acids methyl esters (FAME) in oil (D) extracted from Zygophyllum luntii leaves detected by GC/MS. 
pneumoniae, and Enterococcus spp., and the gram-negative drug resistant bacteria Acinetobacter baumannii, Klebsiella pneumoniae, E. coli, and P. aeruginosa (Lister et al., 2009). Our results also indicated reduced sensitivity of S. aureus and E. coli to Ciprofloxacin. The $Z$. luntii callus extract may help in managing antibacterial resistant pathogens of different strains

\section{Gas Chromatography-Mass Spectrometry (GC/ MS) Analysis}

Higher number of compounds was identified in the leaves $(n=20)$ and stem $(n=19)$ extract compared to roots $(\mathrm{n}=8)$ extracts of $Z$. luntii while 6 compounds could not be identified (Table 1). The retention time (RT) of all compounds varied between 13.64 to 37.7 minutes. The unidentified compounds were present in a relatively low amount. Heneicosane, Docosane and Tricosane were present in higher quantities in the leaves extract. Hop22(29)-En-3.Beta.-Ol (69.95\%) was present in higher quantities in the stem extract while the root extract had octacosane in high quantities. Palmitic acid, linolenic acid and oleic acid were the main components of oil extracted from leaves (Table 2).

Heptacosane, Heneicosane, Tetradecane have been reported with antimicrobial activity (Elshiekh and Abdelmageed, 2015). Beta-acids are an important component of hops (Humulus lupulus L. family Cannabaceae) soft resins and usually isolated as by-products during hop processing (McCallum et al., 2019). Hexahydro- $\beta$ acids showed strong antibacterial activity and good stability (Liu et al., 2019). Noticeably, HOP-22(29)-EN-3. BETA.-OL had the highest percentage compared to other compounds.

Close retention time of 22-27 minutes in roots compounds showed their similar affinity to stationary phase. Both retention time and peak area (\%) for Docosane (C22) and Tricosane (C23) (22.60 minutes and 23.26 minutes, and $12.72 \%$ and $12.93 \%$, respectively) did not show wide variation. These two compounds were present in leaves and roots but not in stems. The n-alkane fractions (hydrocarbons C22-C35) was detected in the leaves extract of $Z$. luntii which have been detected in vegetable oils by GC/MS (Troya et al., 2015). These compounds are more common in plant extracts.

Species of Zygophyllum have been found to contain saponins (Abdel-Khalik et al., 2001), alkaloids (Sharawy and Alshammari, 2009), terpenoids (Perroni et al., 2007), sterols (Shoeb et al., 1994), flavonoids (Ibrahim et al., 2008), proteins and amino acids (Sharma et al., 2010), coumarins (Alam et al., 2010) and trace elements (Fatima et al., 1999). The presence of such chemical ingredients in Zygophyllum spp. Would contribute to the medical properties, including stimulating the immune system in humans, treating and preventing the development of chronic diseases (Beier, 2005), and the vitality to resist such types of pathogenic bacteria used in this study.

\section{Oil Extract from Leaves}

Nine different types of fatty acids methyl esters (FAME) were found in oil extracted from $Z$. luntii leaves. Palmitic acid, Linolenic acid, and Oleic acid were the main compounds and represented $90 \%$ of the oil (Fig.4). There was no study found on $Z$. luntii that explored the fatty acid content. However, seven fatty acids including the Oleic acid, Palmitic acid and Linoleic acid were found in other Zygophyllum species e.g. F. arabica L (Alam et al., 2010) and F. cretica (Soad, 1994).

\section{Conclusion}

Extracts from leaves, stem, and roots of $Z$. luntii had significant antibacterial activity against $E$. coli, $P$. aeruginosa and $S$. aureus. The extracted oils had activity against only $P$. aeruginosa and $S$. aureus. The commercial antibiotic Ciprofloxacin had reduced activity against $S$. aureus and $E$. coli. The $Z$. luntii extracts showed about $50-60 \%$ effectiveness against $E$. coli and $P$. aeruginosa compared to Ciprofloxacin. HOP-22(29)-EN-3. BETA.-OL, Hexahydro- $\beta$ acids, and FAME compounds could have contributed to the antibacterial activity. With further research on callus production, improving extraction process and antimicrobial activity assays against more pathogenic bacterial (including antibiotic resistant) species, $Z$. luntii can be promoted as a source of traditional medicine in Oman

\section{Acknowledgement}

The corresponding author is grateful to postgraduate students at Sultan Qaboos University (SQU) for the GC/ MS analysis, Ruqiya Al Hattali and Hibatallah Al Habsi from the central laboratory from Animal Health for assistance with antibacterial test, Microbiology Laboratory at Sultan Qaboos University Hospital for providing clinical isolates and Dr. Annette Patzelt from Oman Botanic Garden, Diwan of Royal Court for identification of Zygophyllum luntii.

\section{References}

Abdel-Khalik SM, Miyase T, Hanan EA, Melek FR. (2000). Triterpenoid saponins from Fagonia cretica. Phytochemistry 54: 853-859.

Ahsan H, Muhammad Z, Bushra M. (2007). Cytotoxic and antitumor potential of Fagonia cretica L. Turkish Journal of Biology 31(1): 19-24.

Akhtar SM, Hossain MA, Sadri SA. (2017). Isolation and characterization of antimicrobial compound from the stem-bark of the traditionally used medicinal plant Adenium obesum. Journal of Traditional Complementary Medicine 7: 296-300.

Alam EA, Amin GH, ElAyouty YM, Abdel-Hady MS. (2010). Chemical composition and antibacterial ac- 
tivity studies on callus of Fagonia arabica L. Academic Arena 2(12): 91-106.

Al-Salt, J. (2012). Antimicrobial activity of crude extracts of some plant leaves. Research Journal of Microbiology 7:59-67.

Asma HS, Moza TG, Hossain MA. (2017). Brine shrimp toxicity of various polarities leaves and fruits crude fractions of Ziziphus jujuba native to Oman and their antimicrobial potency. Sustainable Chemical Pharmacology 5: 122-125.

Beier BA. (2001). Itvo new unifoliolate species of Fagonia (Zygophyllaceae) from the Horn of Africa region, and the resurrection of F. subinermis from Iran. Nordiac Journal of Botany 21(5): 449-455.

Beier BA. (2005). A revision of the desert shrub Fagonia (Zygophyllaceae). Systematics and Biodiversity 3(3): 221-263.

Bobbarala V. (2015). Concepts, Compounds and the Alternatives of Antibacterials. InTech Open. DOI: 10.5772/59522. eBook.

El-Hefnawi HN. (1994). Screening of some Sinai plants for their antimicrobial activity. Al-Azhar Journal of Microbiology 43: 1-6.

Elshiekh YH, Abdelmageed MAM. (2015). Gas chromatography-mass spectrometry analysis of Pulicaria crispa (whole plant) petroleum ether extracts. American Journal of Research Communication 3(3): 58-67.

Fatima K, Khaula S, Kalhoro MA, Muhammad Q, Yasmeen B. (1999). Trace elements in indigenous medicinal plants (Rhazya stricta, Vinca rosea and Fagonia cretica). Phytochemistry 42(4): 182-183.

Gupta V, Sharma S, Josef I, George M. (2009). Analgesic and antimicrobial activities of Fagonia indica. Pharmacology online 3 .

Hossain MA. (2018). A Review on Adenium Obesum: A Potential Endemic Medicinal Plant in Oman. Beni-Suef University Journal of Basic and Applied Science 7 (4): 559-63.

Hossain MA, AL-Mijizy ZH, Al-Rashdi KK, Weli AM, Al-Riyami Q. (2013). Effect of temperature and extraction process on antioxidant activity of various leaves crude extracts of Thymus vulgaris. Journal of Coastal Life Medicine 1 (2): 118-122.

Ibrahim LF, Kawashty SA, El-Hagrassy AM, Nassar ML, Mabry TJ. (2008). A new kaempferol triglycoside from Fagonia taeckholmiana: cytotoxic activity of its extracts. Carbohydrate Research 343(1): 155-158.

Kunin CM. (1993). Resistance to antimicrobial drugs a worldwide calamity. Annals of Internal Medicine 118:557-561.

Lister PD, Wolter DJ, Hanson ND. (2009). Antibacterial-Resistant Pseudomonas aeruginosa: clinical impact and complex regulation of chromosomally en- coded resistance mechanisms. Clinical Microbiology Review 22(4): 582-610.

Liu Y, Lu N, Tang J. (2019). Synthesis, characterization, crystal structure, and antioxidant activity of hexahydro- $\beta$-acids. Journal of Molecular Structure 1175: 721-727.

Martins E. (2013). The growing use of herbal medicines: issues relating to adverse reactions and challenges in monitoring safety. Frontiers in Pharmacology 4: 177179.

McCallum JL, Nabuurs MH, Gallant ST, Kirby CW, Mill AA. (2019). Phytochemical characterization of wild hops (Humulus lupulus ssp. lupuloides) germplasm resources from the maritimes region of Canada. Frontiers in Plant Science 10:1438.

Mosti S, Raffaelli M, Tardelli M. (2012). Contribution to the flora of central-Southern Dhofar (Sultanate of Oman). Webbia 67(1): 65-91.

Orhan IE. (2012). Biotechnological production of plant secondary metabolites. Bentham e-book, pp. 107120

Oyebode O, Kandala NB, Lilford RJ. (2016). Use of traditional medicine in middle-income countries: a WHOSAGE study. Health Policy Plan 38(8): 984-991.

Perroni A, Masullo MA, Basarello C, Hamed AI, Belisario MA, Pizza C, Piacente S. (2007). Journal of Natural Products 70(4): 584-588.

Pormohammad A, Nasiri MJ, Azimi T. (2019). Prevalence of antibiotic resistance in Escherichia coli strains simultaneously isolated from humans, animals, food, and the environment: a systematic review and meta-analysis. Infect. Drug Resistance 12: 1181-1197.

Raqiya MSM, Hossain MA. (2017). Evaluation of antioxidant and cytotoxic activities of different extracts of folk medicinal plant Hapllophyllum tuberculatum. Egyptian Journal of Basic Applied Science 4: 101-106.

Said MA, Hossain MA, Ahmed AA. (2018). Antimicrobial and cytotoxic comparative study of different extracts of Omani and Sudanese Gum acacia. Beni-Suef University Journal of Basic and Applied Science 7: 22-26.

Sajid B, Alia E, Rizwana K, Uzma S, Hafiz MI. (2011). Phytochemical screening and antimicrobial activity of Fagonia cretica plant extracts against selected microbes. Journal of Pharmacology Research 4:962963.

Satpute RM, Kashyap RS, Deopujiari JY, Taori GM, Daginawala HF. (2009). Protection of PC12 cells from chemical ischemia induced oxidative stress by Fagonia arabica. Food and Chemical Toxicology 47(11): 2689-2695.

Sharawy SM, Alshammari AM. (2009). Checklist of poi- 
sonous plants and animals in Aja Mountain, Ha'il region, Saudi Arabia. Australian Journal of Basic and Applied Science 3(3): 2217-2225.

Sharrma S, Gupta V, Sharma G. (2010). Phytopharmacology of Fagonia Indica (L): A Review. Journal of Natural Conscience 1(1): 143-147.

Shoeb HA, Sharada MM, El-Sayed LAR, El-Wakeel E. (1994). Triterpenoid and sterol glycosides from Fagonia arabica L. Al-Azhar Journal of Pharmaceutical Science 13: 41-48.

Soad MA. (1994). Chemical and Biological studies of some Fagonia species (Family Zygophylllaceae). PhD
Thesis 1994, Department of Pharmaceutical Sciences, Faculty of Pharmacy, Cairo University, Egypt. $\mathrm{p}$ 16-47.

Troy F, Lerma-García MJ, Herrero-Martínez JM, Simó-Alfonso EF. (2015). Classification of vegetable oils according to their botanical origin using $\mathrm{N}$-alkane profiles established by GC-MS. Food Chemistry 167: 36-39.

Zhang W, Krohn K, Draeger S, Schulz B. (2008). Bioactive isocoumarins isolated from the endophytic fungus Microdochium bolleyi. Journal of Natural Products 71(6): 1078-1081. 